\title{
Occupational exposure to petroleum products and its effects on heavy metal metabolism in automobile mechanics
}

\author{
Iyanda Ayobola Abolape* \\ Department of Chemical Pathology, College of Health Sciences, Ladoke Akintola University of Technology, Osogbo, Nigeria.
}

Publication history: Received on 23 December 2018; revised on 16 January 2019; accepted on 21 January 2019

Article DOI: https://doi.org/10.30574/gscbps.2019.6.1.0164

\begin{abstract}
In fuel filling station attendants various pathological events have been linked with exposure to petroleum products, with the severity of these events correlated with blood levels of benzene, toluene, ethylbenzene and xylene (BTEX). BTEX are volatile compounds, so exposure through the nasal route is possible yet in auto-mechanics because dermal exposure is also pronounced, this may lead to the presence of non-volatile petroleum product constituents (e.g. heavy metals) in their systemic. The aim of the study is estimate heavy metal levels in serum of auto-mechanics. Random sampling technique was employed to recruit participating age-matched control and auto-mechanics. Questionnaire was administered, with focus on demographic- age, lifestyle, work experience in years, and work hours, and the type of protective gear used during work hours. Serum obtained from $5 \mathrm{~mL}$ of venous blood was used to estimate levels of lead, aluminium, nickel, silicon, cadmium, and arsenic by atomic absorption spectrometry. Student's t-test was used to determine statistical difference between the means of both groups, $\mathrm{p} \leq 0.05$ was considered significant. The duration of exposure in years was 6- 9 (range) and work-hours (automobile mechanics) per day was an average of 8 hours. All the heavy metals estimated were significantly higher in automobile mechanics compared with control subjects. There are indications that elevated levels of lead, aluminium, nickel, silicon, cadmium, and arsenic is associated with this occupation.
\end{abstract}

Keywords: Auto- mechanics; Heavy metals; Petroleum products; Skin

\section{Introduction}

Safety measures that minimize contact with petroleum products even in people who otherwise would have been hazardously exposed are available. The use of gloves, overall and mask should minimize occupational exposure to components of gasoline [1]. Yet in many developing countries many automobile mechanics have been identified who do not consider these safety precautions important for their day to day activity, so dermal and nasal contact remain an important source of exposure. It would seem reasonable to assume that both dermal and nasal exposure are responsible for blood levels of benzene, toluene, ethylbenzene and xylene (BTEX) in mechanics being volatile compounds but since heavy metals are non-volatile, contact through the dermal route is likely the predominant mean of exposure.

Various heavy metals are found in gasoline and other petroleum products that automobile mechanics are daily exposed to [2-6]. Studies carried out on experimental animals that were treated with petroleum products, established that absorption of these products through the skin can result in increased presence of many heavy metals in the systemic circulation of experimental rats[7]. This suggests that many occupations in which contact with gasoline, diesel, engine oil or kerosene can ensue even in human subjects may lead to heavy metal presence. But the physiologic differences in skin of many mammalian species may make such extrapolation of results difficult.

\footnotetext{
${ }^{*}$ Corresponding author

E-mail address: lapeiyanda@yahoo.com
} 
While the skin that comprises two major layers (i.e. the epidermis and dermis) supplies an organism with a relatively good barrier from its environment, the stratum corneum is the single most important barrier that discourages fluid loss from the body. It also serves as the major barrier that prevents the absorption of foreign, harmful chemicals into the body [8]. Species differences have been identified to affect dermal absorption because of dissimilarity in many components of the skin. Although cutaneous permeability property of guinea pigs, pigs, and monkeys are identical with human subjects, it is generally accepted that dermal absorption via rodent skin is much greater than human skin $[9,10]$.

Therefore, the automobile mechanics are being used to serve as model to determine human response to petroleum products in terms of dermal absorption especially as it relates with heavy metal components of these products.

\section{Material and methods}

\subsection{Subjects, sampling sites and questionnaire administration}

In the workshops, random sampling technique was employed to select suitable participants among automobile mechanics that included diesel-engine mechanics, motor-truck mechanics, engine-repair mechanics, and/or general automobile-mechanics. Male adults recruited for the study i.e. automobile mechanics ( 40 participants) and controls ( 40 participants) were age-matched. Since no form of protective measure was adopted, the auto-mechanics reported of daily dermal contact with petroleum products especially the hands and sometimes other exposed parts of the body.

Control subjects were selected from occupations that are neither gasoline-related nor associated with benzene, xylene or any other major components of petroleum products. In addition, participants with exposure to heavy metal through other occupations or lifestyle (e.g. smoking) were excluded from the study. Inclusion criteria for test subjects are as follows; adult male mechanics with work experience of $>5$ years. Personal data of each participant were obtained through a questionnaire that was administered by a trained person. The main focus of the information obtained through the questionnaire was on demographic- age, education level, smoking status, work experience in years, and work hours, and the type of protective gear used during work hours. The study was carried out in accordance with the revised Helsinki's declaration. Only the individuals that were willing to participate and whose informed consent was obtained were recruited for the study. They were given sufficient information about the purpose and expected outcomes of the investigations. All participants signed the written consent form.

\subsection{Sample collection and heavy metal analysis}

Blood samples were collected from willing participants during their routine work hours. Venous blood samples of about $5 \mathrm{~mL}$ was obtained from the antecubital vein of each participant and dispensed into tubes without anticoagulant. Within 4 hours they were centrifuged and serum stored at $-20^{\circ} \mathrm{C}$. Serum levels of the following metals: lead, aluminium, nickel, silicon, cadmium, and arsenic were determined using the method of atomic absorption spectrometry. Buck Scientific 205 Atomic Absorption supplied by Buck Scientific (East Norwalk, Connecticut, USA) was utilized for these estimations.

\subsection{Statistical analysis}

The SPSS version 15 was used for the analysis of data and used to obtain mean and standard deviation. Student's t test was used to test the statistical significance difference of measured parameters between auto-mechanics and control. A $p$ value of $\leq 0.05$ was considered statistically significant.

\section{Results}

The duration of exposure in years was 6- 9 (range) and work-hours per day was an average of 8 hours. All test subjects revealed non-compliance with usage of protective gear. Over $80 \%$ did not think face mask could have done any good. All had educational status of at least West African Examination Certificate or Senior Secondary School Certificate [equivalent of High School Diploma]. The results of heavy metal estimation are presented in table 1. All of them (Ni, Si, $\mathrm{Al}, \mathrm{Cd}, \mathrm{Pb}, \mathrm{As}$ ) were significantly higher in automobile mechanics compared with control subjects. 
Iyanda/ GSC Biological and Pharmaceutical Sciences 2019, 06(01), 045-049

Table 1 Serum levels of heavy metals of automobile mechanics and control subjects

\begin{tabular}{lllllll}
\hline Subject & As $(\mathrm{ng} / \mathrm{L})$ & $\mathrm{Ni}(\mu \mathrm{g} / \mathrm{L})$ & $\mathrm{Cd}(\mathrm{mg} / \mathrm{L})$ & $\mathrm{Si}(\mu \mathrm{g} / \mathrm{L})$ & $\mathrm{Al}(\mu \mathrm{g} / \mathrm{L})$ & $\mathrm{Pb}(\mu \mathrm{g} / \mathrm{L})$ \\
\hline Control & $150.00 \pm 0.17$ & $0.07 \pm 0.01$ & $0.10 \pm 0.02$ & $0.16 \pm 0.03$ & $0.17 \pm 0.03$ & $0.24 \pm 0.02$ \\
Automobile mechanics & $260.73 \pm 13.22$ & $0.20 \pm 0.2$ & $0.30 \pm 0.05$ & $0.27 \pm 0.03$ & $0.23 \pm 0.05$ & $0.38 \pm 0.04$ \\
P-value & 0.012 & 0.004 & 0.006 & 0.037 & 0.025 & 0.009 \\
\hline
\end{tabular}

Results are expressed as mean \pm standard deviation. $\mathrm{p} \leq 0.05$ is significant.

\section{Discussion}

Many studies have identified that although for fuel filling station attendants, nasal route is a major source of exposure to gasoline (vapour), different routes of exposure have been identified in mechanics. Involuntary exposure through the skin will no doubt be an important mean by which mechanics that do not use protective gear like gloves and overall have contact with petroleum products. Humans are exposed to many toxic chemicals, but the gravity of damage that can occur from dermal contact is dependent on the skin that is relatively impermeable in nature. Notwithstanding, some chemicals are known to be absorbed through the skin in doses large enough to initiate systemic effects. While damage to the skin will undoubtedly enhance rapid absorption of chemicals, evidence exists that suggests that even with uncompromised skin structure/morphology, absorption of toxic chemicals can still take place.

Several insecticides have been reported to produce fatal effects after exposures have occurred in agricultural workers [11]. In some of these workers, the absorption was reported to have occurred through intact skin. Other carcinogenic agents also have been observed to enhance tumor development in other organs after dermal application. While the oral route constitutes another major voluntary route of exposure to petroleum exposure among mechanics, the gastrointestinal tract is much more complex than the skin. The penetration barriers of the skin are much simpler for chemicals in that passage through the stratum corneum is the rate-determining step.

Earlier studies have shown that application of petroleum products through the skin can result in significant presence of their constituents in the systemic of experimental animals. But there are many structural differences in the anatomic features of various species of mammal, which could invariably affect the rate of absorption of a xenobiotic. Differences in absorption of xenobiotics via the skin have been ascribed to peculiarities in anatomic, physiologic, and biochemical factors in many of these experimental animals [8]. Sweat and pilosebaceous ducts may also contribute to this slight species variability. While body surface of humans generally contains 100 to $600 / \mathrm{m} 2$ of coiled tubular sweat glands, rodents have none. Moreover, number of pilosebaceous ducts differs, in humans from rodents, whereas humans and pigs have similar number of about $40 / \mathrm{cm} 2$, rodents may have up to 100 times more. All these basic differences suggest that the type of chemical agents that cross the dermis and epidermis and reflect in the systemic will vary across species. The significant elevation in the serum levels of the heavy metals estimated in mechanics compared with control is in agreement with results of earlier studies carried out on experimental animals. Iyanda and Iheakanwa [12] revealed that after dermal administration of engine oil many heavy metals were significantly higher when compared with control. This means that despite anatomical differences, absorption of heavy metal constituents of petroleum products takes place in different mammalian species.

Toxic xenobiotics are transported across the stratum corneum by passive diffusion, but for lipophilic (fat soluble) compounds, they are more readily transferred across the stratum corneum, which is probably the basis of BTEX presence in not only mechanics but also the fuel filling station attendants, as it was reported by Tunsaringkarn et al. [13]. On the other hand, penetration of hydrophilic (water-soluble) compounds is comparably limited. According to Rice and Mauro [11] the rate of absorption of nonpolar toxicants is in a manner that is proportional to their lipid solubility and inversely related to molecular weight. Aside stratum corneum, there are other diffusion barriers in the lower layers of the epidermis, examples being stratum granulosum, spinosum, and germinativum, although these are by far inferior compared with stratum corneum. The significantly high levels of heavy metals observed in the mechanics compared with control suggest that many of these barriers could not effectively prevent heavy metal absorption through the dermal route. Although, other important factors such as blood flow, interstitial fluid movement, and interactions with dermal constituents affect the rate of diffusion. Toxicants that are absorbed through the skin by diffusion enter the systemic circulation via the numerous venous and lymphatic capillaries in the dermis. It is this mechanism that has been suggested to be the basis of high serum heavy metals in users of heavy-metal containing cosmetics [14]. 
Exposure to petroleum products is known to induce genotoxicity, while studies abound that have related BTEX to the genotoxic effects of gasoline, very many heavy metals some of them constituents of crude oil from which petroleum products are obtained are known to interact with DNA upon absorption to cause genotoxicity. Rekhadvi et al. [15] estimated the degree of genotoxicity and petrol exposure in blood and urine samples of workers exposed to fuel in filling stations, and results showed that there was exposure to BTX in petrol vapors as well as increase in the frequency of micronuclei (MN) and CA in the exposed subjects than in controls. According to many studies male breast cancer incidence has been associated with chemical-related occupations. Their findings indicated that some environmental chemicals are possible mammary carcinogens. They opined that exposure to gasoline, organic petroleum solvents or polycyclic aromatic hydrocarbons (PAHs) may be suspected from the consistent elevated risk of male breast cancer observed in motor vehicle mechanics. A number of vital pathways are derailed post-PAHs exposure; according to Villeneuve et al. [16] endocrine disruptors such as alkyl phenolic compounds may play a role in the pathogenesis of breast cancer. Even with these various submissions that have linked breast cancer or other cancers to different aromatic constituents of gasoline, heavy metal-induced malignancies have also been reported. A role of heavy metals in the initiation and progression of many disorders associated with gasoline exposure cannot be ruled out.

Data obtained from the study showed negligence by the auto-mechanics with regards to self-protection. There were no defined efforts, in relation to any set of rules and regulations for worker safety in any of the automobile mechanic workshops included in the study. Lack of awareness with respect to chemical hazards among mechanics was also observed. There ought to be laws to protect the apprentices working under them that are exposed to the same working conditions.

It is essential that appropriate regulatory bodies be up to the task in their role in the safety of auto-mechanics. Exposed workers themselves need to be sensitized on the need for them to adopt necessary protective measures that will guarantee their wellbeing. It is not surprising that life expectancy is quite low in Nigeria. The nonchalant attitude of automobile mechanics as well as many others in occupations that predispose them to a variety of chemicals is capable of not only reducing quality of life but affect life expectancy.

\section{Conclusion}

Elevated levels of lead, aluminium, nickel, silicon, cadmium, and arsenic were observed in sera of auto-mechanics, suggesting that this occupation is with heavy metal toxicity. Through further study, it seems necessary to identify whether these elements play a contributory role as aetiologic factors in many pathological events commonly associated with this occupation.

\section{Compliance with ethical standards}

\section{Acknowledgments}

The author acknowledges the assistance of Mrs. V. B. Adekoya and Mr. J. O. Agbokhade of the Experimental Animal Unit of the Faculty of Veterinary Medicine, University of Ibadan in the care of experimental animals.

\section{Disclosure of conflict of interest}

There is no conflict of interest with publishing the present data of the study.

\section{Statement of ethical approval}

All procedures were carried out in accordance with revised Helsinki Declaration.

\section{Statement of informed consent}

Informed consent was obtained from all individual participants included in the study.

\section{References}

[1] Kamal A, Cincinelli A, Martellini T, Palchetti I, Bettazzi F andMalik RN. (2015). Health and carcinogenic risk evaluation for cohorts exposed to PAHs in petrochemical workplaces in Rawalpindi city (Pakistan). International Journal of Environmental Health Research, 5, 1-21. 
[2] Onunkwor B, Dosumu O, Odukoya 00, Arowolo T andAdemuyiwa 0. (2004). Biomarkers of lead exposure in petrol station attendants and auto-mechanics in Abeokuta, Nigeria: effect of 2-week ascorbic acid supplementation. Environmeental Toxicology and Pharmacology, 17(3), 169-76.

[3] Osuji LC, Onojake CM. 2004. Trace heavy metals associated with crude oil: a case study of Ebocha-8 oil-spillpolluted site in Niger Delta, Nigeria. Chemistry and Biodiversity, 1(11), 1708-15.

[4] Chen F, Jiang S. 2009. Determination of $\mathrm{Hg}$ and $\mathrm{Pb}$ in fuels by inductively coupled plasma mass spectrometry using flow injection chemical vapour generation. Analytical Sciences, 25, 1471-6.

[5] Al-Ghouti MA, Al-Atoum L. 2009. Virgin and recycled engine oil differentiation: a spectroscopic study. Journal of Environmental Management, 90(1), 187-95.

[6] Kim Y, Kim NY, Park SY, Lee DK, Lee JH. 2013. Classification and individualization of used engine oils using elemental composition and discriminant analysis. Forensic Science International, 230(1-3), 58-67.

[7] Iyanda AA. 2014. Kerosene: A study of serum levels of select heavy metals and histology of brain, lung, heart and ileum of rats chronically exposed. British Journal of Pharmaceutical Research, 4(6), 731-738.

[8] Poet TS, McDougal JN. 2002. Skin absorption and human risk assessment. Chemico-Biological Interaction, 140, $19-34$.

[9] Wester RC, Maibach HI. (1993). Animal models for percutaneous absorption, in Wang RGM, Knaak JB, Maibach HI (eds.): Health Risk Assessment- Dermal and Inhalation Exposure and Absorption of Toxicants. Boca Raton: CRC Press, 89-103.

[10] Ross JH, Driver JH, Harris SA, Maibach HI. 2005. Dermal absorption of 2, 4-D: A review of species differences. Regulatory Toxicology and Pharmacology, 41, 82-91.

[11] Rice RH, Mauro TM. 2008. Toxic responses of the skin. In Casserret and Doull's Toxicology the basic science of poisons. Editor CD Klaassen. 7th edition, pg 741-760.

[12] Iyanda AA, Iheakanwa CI. 2018. Evaluation of heavy metal levels in serum of wistar rats exposed to engine oil. Progress in Health Sciences, (in print).

[13] Tunsaringkarn T, Siriwong W, Rungsiyothin A, Nopparatbundit S. 2012. Occupational Exposure of Gasoline Station Workers to BTEX Compounds in Bangkok, Thailand. The International Journal of Occupational and Environmental Medicine, 3, 117-25.

[14] Iyanda AA, Anetor JI, Adeniyi FAA. 2011. Altered copper level and renal dysfunction in Nigerian women using skin-whitening agents. Biological Trace Element Research, 143(3), 1264-1270.

[15] Rekhadevi PV, Mahboob M, Rahman MF, Grover P. 2011. Determination of genetic damage and urinary metabolites in fuel filling station attendants. Environmental and Molecular Mutagenesis, 52(4), 310-8.

[16] Villeneuve S, Cyr D, Lynge E. 2010. Occupation and occupational exposure to endocrine disrupting chemicals in male breast cancer: a case-control study in Europe. Occupation and Environmental Medicine, 67(12), 837-844.

\section{How to cite this article}

Iyanda AA. (2019). Occupational exposure to petroleum products and its effects on heavy metal metabolism in automobile mechanics. GSC Biological and Pharmaceutical Sciences, 6(1), 45-49. 